\title{
Influential Parameters and Numerical Simulation of Heat Generated in the Process of Friction Stir Welding
}

\author{
Ilija KOVACEVIC, Mirko DJELOSEVIC*, Goran TEPIC, Stevan MILISAVLJEVIC
}

\author{
Faculty of Technical Sciences, University of Novi Sad, Trg Dositeja Obradovica 6, 21000 Novi Sad, Serbia \\ cross $^{\text {ref }}$ http://dx.doi.org/10.5755/j01.ms.22.3.10022
}

Received 21 February 2015; accepted 19 June 2015

\begin{abstract}
The paper analyzes the problem of friction stir welding (FSW) technology. The mechanism of thermo-mechanical process of the FSW method has been identified and a correlation between the weld zone and its microstructure established. Presented are the basic analytical formulations for the definition of temperature fields. Analysis of influential parameters of welding FSW technology at the zone of the weld material and mechanical properties of the realized joint was performed. Influential welding parameters were defined based on tool geometry, technological parameters of processing and the axial load of tool. Specific problems with the FSW process are related to gaps (holes) left behind by a tool at the end of the process and inflexibility of welding regarding the degree of variation of material thickness. Numerical simulation of process welding FSW proceeding was carried out on the example of Aluminum Alloy (AA 2219) using the ANSYS Mechanical ADPL (Transient Thermal) software package. The defined was the temperature field in the welding process at specified time intervals.

Keywords: friction stir welding, heat generation, thermo-mechanical process, numerical simulation, joining of material.
\end{abstract}

\section{INTRODUCTION}

Modern conditions of production from technology of welding procedures require very specific requirements in terms of joining of different materials and light metal alloys, which cannot be realized using conventional methods of welding. Key indicators of effectiveness of applied welding technique are manifested through the weld-joint quality and accuracy of positioning elements in the joint. The need for additional processing of welded elements directly depends on these parameters, which also affect the reduction of manufacturing costs. The development of welding technology in this direction initiated a new method known as friction stir welding (FSW). This welding process was developed by Thomas et al. [1] from the WTI (UK) and results of their research were first presented in 1991. Unlike the classical method for joining materials by friction, heat generation in the FSW method is achieved through a special cylindrical tool with tapered pin, whose role is to stir the heated material along the joint line [2]. Achieving a highquality of joint requires its heating to the temperature that ensures a full diffusion of materials (for diffusion welding procedures). If higher amounts of heat are introduced during the welding process than the minimum required for completing the diffusion process, the heat affected zone (HAZ) characterized higher structural changes, which adversely influences the mechanical properties of the joint [3]. In conventional welding processes, the possibility of introducing heat in a controlled manner is reduced to a minimum, due to difficulties in managing welding parameters, particularly if welding is carried out manually [4]. The appearance of cracks, residual stresses, harmful gases and vapors, as well as the porous structure and the need for eliminating oxides from the metal are the basic

\footnotetext{
* Corresponding author. Tel.: +381-21-4852429; fax: +381-21-450644.

E-mail address: djelosevic.m@uns.ac.rs (M. Djelosevic)
}

shortcomings of conventional welding processes (MAW, MIG, MAG, TIG etc.) [5]. The FSW welding technology is characterized by a complex mechanism of tribological, mechanical, metallurgical and thermal processes. Since materials are not joined merely under the influence of the heat, mechanical deformation also plays an important role. The amount of heat input in the FSW method is around 20\% compared to traditional methods of arc welding (MMAW and MIG/MAG) [6]. Due to the complexity of physical processes, theoretical research dealing with the FSW technology is limited and it is mostly based on simplified thermo mechanical models [7]. As a result, the analysis of thermo mechanical joining is primarily based on numerical modeling and experimental testing. Typical studies of this problem are given by researcher: Chen and Kovacevic [8], Zhang et al. [9], Kiral et al. [10] and Chao et al. [11].

\section{MECHANISMS OF THERMO MECHANICAL PROCESS IN THE FSW PROCEDURE}

The principle of operation the FSW technology is based on the generation of heat, induced through the tribological process by mechanical action of a special tool in contact with the base material (Fig. 1). The initiation of the FSW process is characterized by transformation of the mechanical work of friction between the rotating tool and the elements to be welded into thermal energy. This thermal energy reduces the material's resistance to plastic deformation.

During the process additional heat is being generated as a result of the materials' plastic dissipation. The relationship between these two parameters is the pin diameter; with the increase of pin diameter, the share of plastic dissipation also increases at the expense of the reduction of the heat generated in the shoulder-plate contact [12]. Layers of the base material directly affected by the tool surface are rotating along it, while the rest of the material opposes this dynamic process. Given the cohesive bond between the 
layers of materials in the welding zone, they rotate at different speed, resulting in intensive development of local heat. This indicates that the mechanism of weld joint formation using the FSW method is based on a combination of mechanical and thermal processes. The mechanical work of the rotating tool is partially distributed into initial heat, while the rest is transformed into deformation energy. The initially generated heat is exclusively the result of a tribological process and aims to increase the material's plasticity by reducing their mechanical properties (hardness and strength).

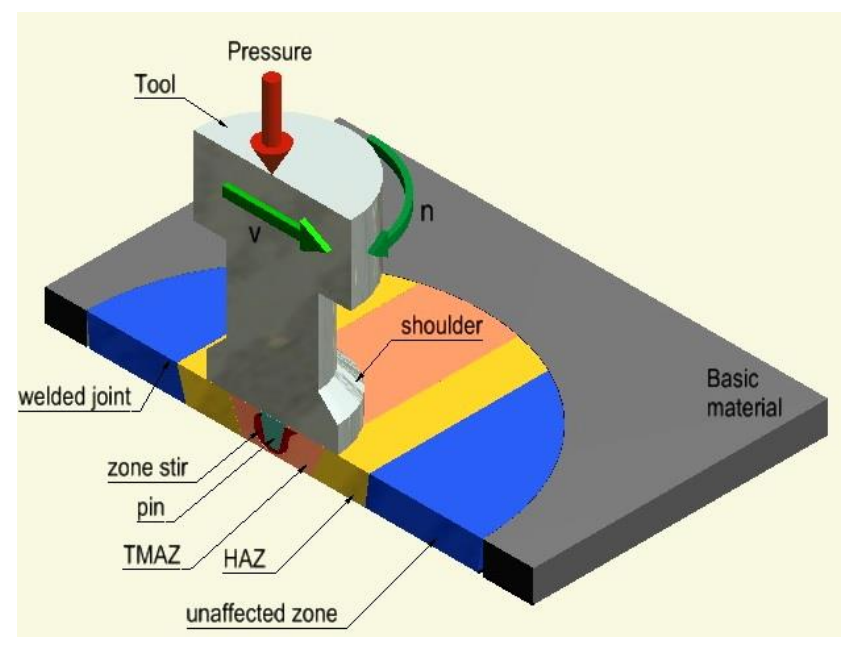

Fig. 1. The principle of the FSW process and zones of influence

Material plasticity ensured in this way facilitates the process of material dissipation in the immediate zones of the tool, thus creating additional heat. The largest portion of heat (about $88 \%$ ) transfers to the base material, while the remainder transfers to the tool [12]. Interacting with the deformation, the overall heat generated acts in a stirring zone, where the permanent mixing of the heated and now highly plastic material takes place, achieving thereby the homogenization of materials along the joint. This heat generating mechanism provides the minimum heat input (compared to the diffusion processes), which is required to achieve only a "pasty" material. Donne et al. [13] analyzes the influence of residual stresses in the FSW method that have a minimal effect. This effect is particularly significant for the exact identification of the local stress [14].

\section{ANALYTICAL MODEL OF THERMO MECHANICAL PROCESSES}

The cylindrical tool (shoulder and pin) rotates with constant speed whose is the pin inserted within the workpiece. The mass flow is treated as a flow of a nonNewtonian, incompressible, viscoplastic material. The continuity equation for incompressible single phase flow is given by:

$\frac{\partial u_{i}}{\partial x_{i}}=0$

where $u$ is the velocity of plastic flow, while the index $i$ representing directions $x, y$ and $z$, respectively.

Although energy can be converted from one form to another, the total energy in a given closed system remains constant. The steady single phase momentum conservation equations in relation to the coordinate system that is tied for source of heat (the movable tool) index form may be represented as:

$$
\rho \frac{\partial u_{i} u_{j}}{\partial x_{i}}=-\frac{\partial P}{\partial x_{j}}+\chi \frac{\partial}{\partial x_{i}}\left(\frac{\partial u_{j}}{\partial x_{i}}+\frac{\partial u_{i}}{\partial x_{j}}\right)-\rho v \frac{\partial u_{j}}{\partial x_{j}},
$$

where $\rho$ is the density; $\chi$ is the non-Newtonian viscosity; $v$ is the welding velocity and $P$ is the pressure.

The steady thermal energy conservation equation is given by:

$$
\rho C_{p} \frac{\partial\left(u_{i} T\right)}{\partial x_{i}}=-\rho C_{p} v \frac{\partial T}{\partial x_{i}}+\frac{\partial}{\partial x_{i}}\left(k \frac{\partial T}{\partial x_{i}}\right)+\left[\frac{S(\theta) A_{r}}{V}\right],
$$

where $C_{p}$ is the specific heat and $k$ is the thermal conductivity of the weld material. $S(\theta)$ represents the heat generation rate per unit area in contact the tool pin and workpiece.

$$
S(\theta)=C_{f} \tau(\omega r-v \sin \theta),
$$

where $C_{f}$ is the power efficiency factor and representing the amount of mechanical energy converted to heat energy and $\omega(=2 \pi n)$ is angular velocity of tool; $n$ is the number of revolution per second.

The terms $(\omega r-v \sin \theta)$ represent the relative velocity of the tool with respect to the material. The parameter $\theta$ refers to the angle which the point on the cylindrical surface of the tool forms with the direction of its motion and is given by:

$\theta=\arcsin \left(\frac{y}{\sqrt{x^{2}+y^{2}}}\right)$

Taking into account that the process of slip thermally activated, issue of temperature effect can be correlated with the rate strain influence with exponential equation, forms:

$\varepsilon=\varepsilon_{0} e^{\frac{E_{0}-\lambda \tau}{k T}}$,

where $\varepsilon_{0}$ is the maximum fully activated strain rate; $E_{0}$ is the activation energy; $\lambda$ is the activation volume; $T$ is the absolute local temperature.

Corresponding shear (flow) stress $\tau$ is obtained from the Eq. 6 and has the form:

$\tau=\frac{E_{0}}{\lambda}-\frac{k}{\lambda} \ln \dot{\varepsilon}_{0} T+\frac{k}{\lambda} T \ln \dot{\varepsilon}$.

Analogous form is given by Miller [15], assuming that the small variations of temperature.

$\tau=97.7+3.02 \ln \dot{\varepsilon}$.

The continuity of the heat flux is provided through the boundary conditions in the contact zone of tool and workpiece. The heat flux at the surface of contact of the shoulder tool and the workpiece corresponds the rate of heat generation which is caused by the influence of plastic work in this zone. This work according to Nandan et al. [16] has been formulated as:

$q=C_{f}\left[\phi \tau\left(\omega \sqrt{x^{2}+y^{2}}-v \sin \theta\right)+(1-\phi) \mu P\right]$,

where $\phi$ is the coefficient of sticking material workpiece for extent of tools. If it is $\phi=1$, sticking is completely and all the heat is generated by plastic deformation. When $\phi=0$, the entire heat generated is transformed into the work of friction. 
The local heat generation can be calculated by the following expression:

$q_{S}=2 \pi n \mu R_{P} P$.

The heat generated by the tool pin consists of the following three parts and is given by Song and Kovacevic [17]:

1. Heat generated by shearing of the material.

2. Heat generated by the friction on the threaded surface of the pin.

3. Heat generated by friction on the vertical surface of the pin.

$$
\begin{aligned}
q_{P}= & \frac{2 \pi R_{P} t k \tau \sin \varphi}{\sin \left(180^{0}-\alpha-\varphi\right)}+\frac{4 F_{P} \mu \sin \varphi \cos \alpha}{\pi \sin \left(180^{0}-\alpha-\varphi\right)}+ \\
& +\frac{2 \mu k \tau \pi R_{P} t \sin \alpha}{\sin \left(180^{0}-\alpha-\varphi\right) \sqrt{3\left(1+\mu^{2}\right)}},
\end{aligned}
$$

where $t$ is the thickness of the workpiece; $\mu$ is the friction coefficient; $F_{P}$ is the translation force during the welding; $\tau$ is the average shear stress of the material and $\varphi$ is the helix angle of the thread.

The boundary condition for heat exchange between the top surface of the workpiece and the surroundings beyond the shoulder is refers to convective and radiative heat transfer, as follows:

$$
\begin{aligned}
& \left.-\left.k \frac{\partial T}{\partial z}\right|_{\text {shoulder }}=\sigma \varepsilon\left(T^{4}-T_{0}^{4}\right)+h\left(T-T_{0}\right)\right) ; \\
& \left.k \frac{\partial T}{\partial z}\right|_{\text {bottom }}=h\left(T-T_{0}\right) \\
& \left.k \frac{\partial T}{\partial n}\right|_{\text {shoulder }}=q_{S}, \\
& \left.\left.k \frac{\partial T}{\partial n}\right|_{\text {pin }}=q_{P}\right\}
\end{aligned}
$$

where $\sigma$ is the flow stress which is determined in accordance with terms given by Nandan et al. [16].

Stationarity of the total energy for a differential volume element in the vicinity of the pin tool is given by:

$$
\frac{\partial \gamma_{i j}}{\partial t}+\frac{\partial}{\partial x_{i}}\left(k \frac{\partial T}{\partial x_{i}}\right)-\rho v_{i} \frac{\partial e}{\partial x_{i}}=0 \text {. }
$$

The expression that defines the plastic work $E$ outside the zone of plastic flow is transformed into the form $E=C T$, where $C$ is the specific heat of the metal. When this applied to the (14), we have:

$$
\frac{\partial^{2} T}{\partial x^{2}}+\frac{\partial^{2} T}{\partial y^{2}}-\frac{v}{\beta} \frac{\partial T}{\partial x}=0 \text {. }
$$

Solution of partial differential Eq. 15 gives the temperature field around a moving heat source (tool) along the direction of its motion $(-a<x<a)$ and has the form:

$T(x, y)=\frac{E_{i n}}{2 \pi k} \int_{-a}^{a} e^{\frac{v x}{2 \delta}} K_{0}\left[\frac{v \sqrt{(x-x)^{2}+y^{2}}}{2 \delta}\right] d x$,

where $E_{i n}$ is the input energy from the translation and rotation; $K_{o}$ is the modified Bessel function of the second kind of order zero and parameter $\delta$ is the ratio $(k / \rho)$.

The form of the temperature profile is shown in Fig. 2.

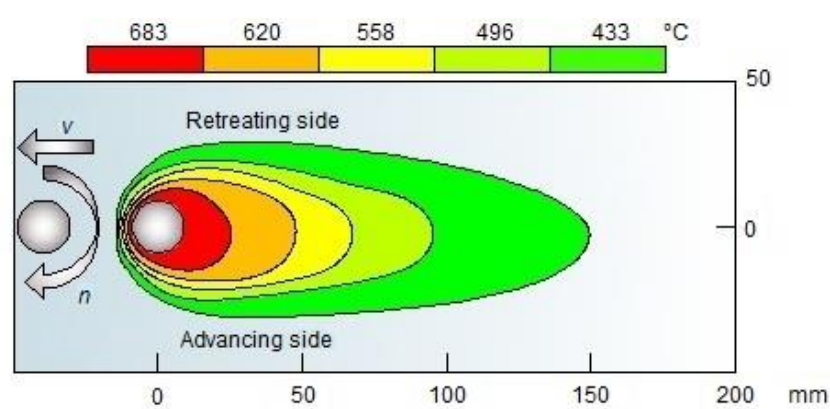

Fig. 2. The temperature profile of the FSW weld

\section{STRUCTURE OF THE WELDED JOINT OBTAINED USING THE FSW TECHNOLOGY}

Generation of temperature and the resulting intense plastic deformation in the FSW process is manifested through the process of recrystallization and the development of texture in the stir zone and its vicinity. Based on the microstructure of the joint [18], three distinctive zones can be identified: stir zone, thermo mechanically affected zone (TMAZ) and heat affected zone (HAZ). Micro structural changes in these zones are important for the mechanical properties of welded joint and thus, they are subjects of numerous studies $[19,20]$.

The thermo mechanically affected zone (TMAZ) is characterized by the zone between the base material (Fig. 3 a) and the stir zone (Fig. 3 b), and it is exposed to the effects of temperature and mechanical strains (Fig. $3 \mathrm{c}$ ). In TMAZ, the heat dissolves the copper atoms which bond with the aluminum atoms forming a fine-grained structure of good mechanical properties in the process of intensive plastic deformation induced by the tool [18].

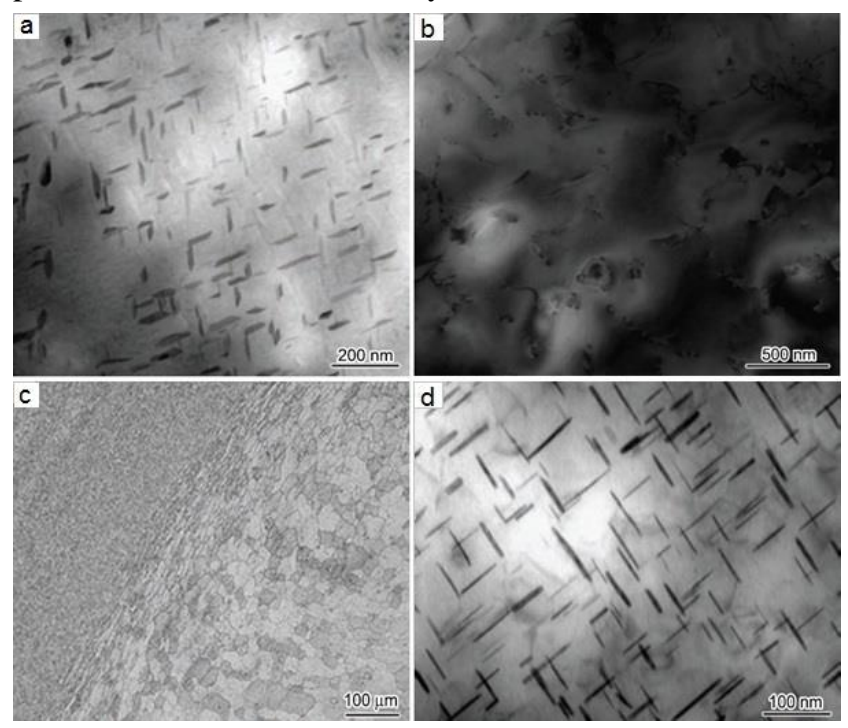

Fig. 3. Microstructure the AA2219 alloy [11] for: a-the base material; $\mathrm{b}$-the stir zone; c-TMAZ (advancing side); d - HAZ

This zone may be in the form of irregular grains having a tendency of becoming wider in the vicinity of the upper surface or taking elliptical shape. The first case corresponds to the lower tool rpm's $\left(300 \div 500 \mathrm{~min}^{-1}\right)$, while higher angular velocities correspond to other stir zone forms. This indicates that the same tool geometry, under different processing parameters induces differences in the joint 
structure (Fig. 4). The shape of the stir zone depends on the process parameters, tool geometry, the temperature of the sample processed, and the materials' thermal conductivity. In the narrow zone close to the stir zone it is characterized by the process of recrystallization of materials.

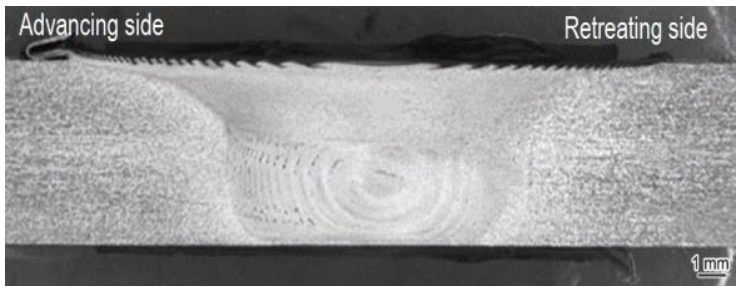

Fig. 4. Macrostructure of the FSW weld [11]

The heat affected zone (HAZ) is the zone that has not undergone to plastic deformation (Fig. $3 \mathrm{~d}$ ). Under the influence of heat in this zone, the grain size remained unchanged in comparison with the base material, but there has been a change in the structure of residue as a result of the progressive dissolution of copper atoms at higher temperatures (especially over $400{ }^{\circ} \mathrm{C}$ ). Parameters affecting the micro and macro structure of the FSW weld are given in Section 5.

\section{INFLUENTIAL PARAMETERS OF THE GENERATED HEAT IN THE FSW TECHNOLOGY}

The heat generation process in the FSW procedure was first presented in the study [19]. Analytical methodology has an important place in the analysis of heat generation process, which in conjunction with numerical and experimental approach complements the procedure of identifying the FSW process. Analytical approaches have been developed since 2002, and a total of four models were presented. The first model assumes that the heat generation process is based on pure friction [19], while the second model, in addition to friction, also includes a deformation mechanism assuming that they identically influence the heat induction [21].

The third model is a modification of the preceding, which provides friction with greater influence in the heat generation process [17]. The fourth model is the most complex because it assumes that only part of the mechanical energy is transformed into heat, while the remainder is involved in other related processes depending on tribological parameters, tool geometry, sample temperature, material flow around the tool and the heat propagation [22, 23]. Influential parameters of FSW technology include: i) Welding tool geometry, ii) Technological parameters of the process, and iii) Axial load of tool. Tool geometry is the most influential factor affecting the development of the FSW process [24], and its primary function is to localize the heat and material flow (Fig. 5). From the aspect of heat, the relative size of the shoulder is particularly important as well as the conical part of the tool. The edge portion has a role of retaining heat along the tool volume, while the conical part ensures stirring the pasty material ensuring good material incorporation and high joint structure quality. Uniformity of microstructure and the correct mechanical properties of the joint are achieved using appropriate tool geometry with concave rim and tapered part of the tool with thread (Fig. 5). Tool materials depend on the sample material and the welding parameters, and can be: $\mathrm{H} 13$ tool steel (for $\mathrm{Al}$ and $\mathrm{Mg}$ alloys), X155CrMoV12-1 (Cu and its alloys), polycrystalline cubic boron nitride, and tungsten (for steel, titanium and their alloys).

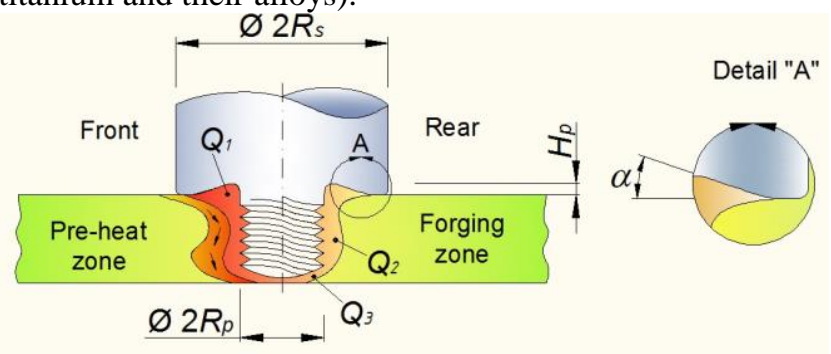

Fig. 5. The tool in the stir zone

Different mechanical properties of the welded joint can be obtained by applying different welding regimes (rpm, direction of the tool rotation, the tool's translational velocity and its inclination angle with respect to the piece), while retaining the same tool geometry. The axial pressure of the tool directly affects the generated heat: insufficient pressure results with defects in the seam, while excess pressure leads to deformation of the upper joint edge [25].

The influence of the individual tool surfaces on the overall heat energy generated is dependent on its geometry and the partial components given by Schmidt et al. [19]:

$f_{S}=\frac{Q_{1}}{Q_{T}}=\frac{\left(R_{S}^{3}-R_{P}^{3}\right)(1+\operatorname{tg} \alpha)}{\left(R_{S}^{3}-R_{P}^{3}\right)(1+\operatorname{tg} \alpha)+R_{P}^{3}+3 R_{P}^{2} H_{P}}=0.86 ;$

$f_{P S}=\frac{Q_{2}}{Q_{T}}=\frac{3 R_{P}^{2} H_{P}}{\left(R_{S}^{3}-R_{P}^{3}\right)(1+\operatorname{tg} \alpha)+R_{P}^{3}+3 R_{P}^{2} H_{P}}=0.11 ;$

$f_{P T}=\frac{Q_{2}}{Q_{T}}=\frac{R_{P}^{3}}{\left(R_{S}^{3}-R_{P}^{3}\right)(1+\operatorname{tg} \alpha)+R_{P}^{3}+3 R_{P}^{2} H_{P}}=0.03$,

where tool dimensions are as follows: $R_{S}=9 \mathrm{~mm}$, $R_{P}=3 \mathrm{~mm}$ and $H_{P}=4 \mathrm{~mm}$ and $\alpha=10^{\circ}$ (Fig. 5).

Terms $(17-19)$ show that the largest share $(86 \%)$ in inducing heat is that of the tool rim (part of the tool with the highest circumferential velocity), while the lowest share is that of the tool tip (only $3 \%$ ). Based on the above facts that characterize the FSW technology, it is concluded that this method has a number of advantages over conventional welding methods, which are based on the process of material diffusion. FSW is the most energy efficient method (the amount of heat input is only $20 \%$ compared to the MIG process). The FSW technology is particularly important in the aviation industry, where traditional rivets were replaced by this method. Tanks for liquid oxygen and hydrogen in spacecrafts are manufactured using the FSW process from the AA2219 alloy. Simulation of the FSW method using AA2219 alloy plates is discussed next in this paper.

\section{NUMERICAL SIMULATION OF TEMPERATURE GENERATED IN THE FSW METHOD}

Numerical simulation of the FSW technology was carried out using the finite element method (FEM) in the corresponding module of the ANSYS Mechanical software ADPL (Transient Thermal). The finite element meshes were generated using three-dimensional shell elements, which were defined as Shell 3D 4node 57. The generated finite 
element mesh has a non-uniform configuration, with higher density along the heat source's (tool) advancing line. Its purpose is achieving higher accuracy, since higher numbers of nodal points are concentrated in zones gravitating in the immediate vicinity of the tool (Fig. 6).

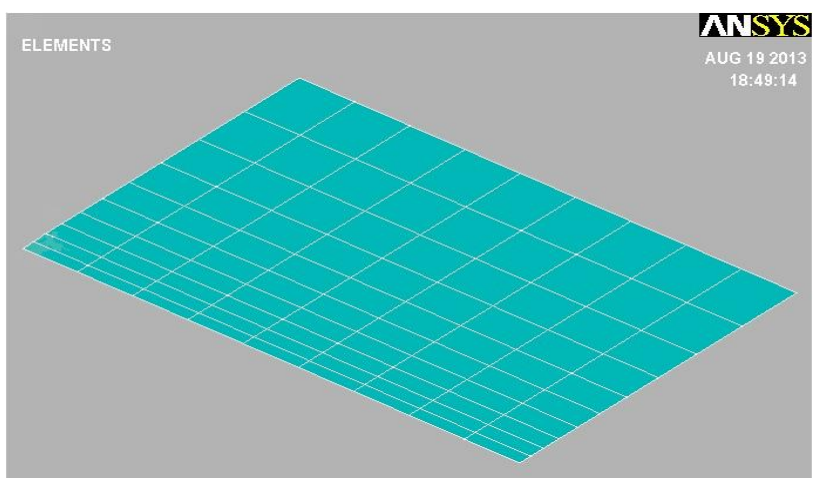

Fig. 6. The generated finite element meshes

Simulation refers to welding the AA 2219 alloy sample of dimensions $5 \times 200 \times 200 \mathrm{~mm}$. The alloy's thermal conductivity is $237 \mathrm{~W} /(\mathrm{mK})$, with its specific heat of $900 \mathrm{~J} /(\mathrm{kgK})$ and material density $2720 \mathrm{~kg} / \mathrm{m}^{3}$. The sample is formed by welding two identical elements $(5 \times 200 \times 100) \mathrm{mm}$ along the sides of greater length, which represents a welded joint. Given the symmetry present, the analysis is performed only for one of the elements, wherein the general nature of the numerical procedure is uncompromised. Results of the analysis are shown in Fig. $7 \mathrm{a}-$ e. Temperature gradients shown in these figures can be generalized for other values of material thickness in the range of $3-12 \mathrm{~mm}$ with a maximum deviation of $8 \%$. Based on the simulation it has been concluded that the beginning of the process is characterized by localized temperatures around the joint zone (mobile heat source) with a radial temperature gradient, which is a product only of heat generated by the tool operation. In the continuation of the process, temperature of the point along joint is the result of the tool operation and the temperature gradient of the previous point at which the heat source is operated. This causes the appearance of elongated local temperature field (immediately next to the tool). Depending on the welding speed and the material's thermal conductivity, pre-heating occurs in the material which facilitates the welding process. This phenomenon has its extreme impact at the very end of the process when the maximum temperature value occurs, in spite the constant temperature value generated by the mobile heat source (tool) throughout the entire welding process. The value of temperature $T$ at the end of the process as a function of the welding regime $(n, v)$ is given in Table 1 .

Table 1. Temperatures as a function of welding parameters

\begin{tabular}{|c|c|c|c|}
\hline Case & $\begin{array}{c}\text { Rotation } \\
\text { speed } n, \mathrm{r} / \mathrm{min}\end{array}$ & $\begin{array}{c}\text { Transverse } \\
\text { speed } v, \mathrm{~cm} / \min \end{array}$ & $\begin{array}{c}\text { Temperature } \\
T,{ }^{\circ} \mathrm{C}\end{array}$ \\
\hline 1 & 400 & 6 & 652 \\
\hline 2 & 500 & 9 & 661 \\
\hline 3 & 600 & 12 & 669 \\
\hline 4 & 700 & 15 & 672 \\
\hline 5 & 800 & 18 & 683 \\
\hline 6 & 900 & 21 & 695 \\
\hline 7 & 1000 & 24 & 711 \\
\hline
\end{tabular}

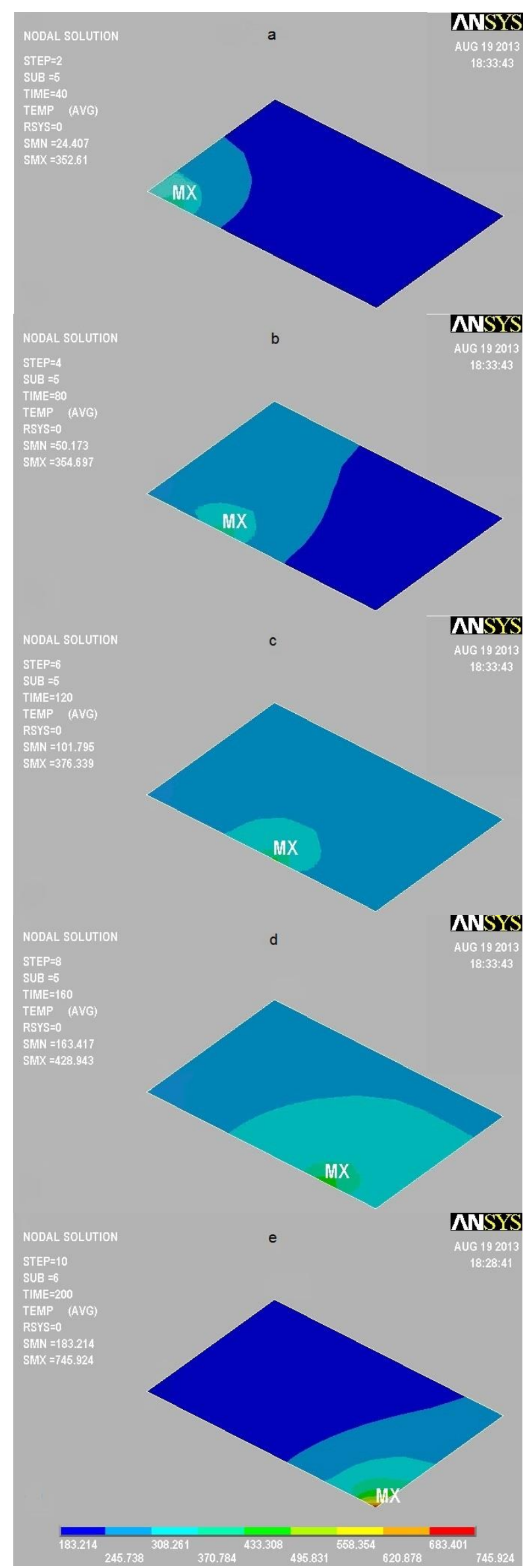

Fig. 7. Development of temperature during the FSW process given for time periods as from the beginning of welding: $a-20 \mathrm{~s}$; $\mathrm{b}-80 \mathrm{~s} ; \mathrm{c}-120 \mathrm{~s} ; \mathrm{d}-160 \mathrm{~s} ; \mathrm{e}-200 \mathrm{~s}$ 


\section{CONCLUSIONS}

The present study has analyzed the welding parameters influencing the FSW process. Heat inducing mechanisms of this welding process, zones of influence and the structure of the welded aluminum-alloy joint were analyzed. Advantages over conventional welding processes were identified, such as high quality seam, without porosity, crack and the need for removing oxide, with special emphasis on the minor influence of residual stresses. By using analytical expressions for thermo mechanical processes, defined is temperature field of a moving heat source (tool).

Numerical simulation of the FSW welding technology was discussed in order to analyze the development of temperature field, using the ANSYS Mechanical ADPL software. The presented temperature gradient results are valid for material thickness in the range of $3-12 \mathrm{~mm}$, which is identified by simulating with the same welding regimes for thickness levels of this range. Knowing the distribution of the temperature field (temperature gradient) can provide great assistance in the planning of experiments to analyze the optimal welding parameters, reducing both the scope and costs of testing. The importance of numerical modeling of thermo mechanical processes is reflected in the possibility of identifying relevant parameters affecting the welding process and the further development of this area.

\section{Acknowledgments}

The author's acknowledgement the support of research project TR 36030, funded by the Ministry of Education, Science and Technological Development of Serbia.

\section{REFERENCES}

1. Thomas, W.M., Threadgill, P.L., Nicholas, E.D. Feasibility of Friction Stir Welding Steel Science and Technology of Welding and Joining 4 (6) 1999: pp. 365-372.

http://dx.doi.org/10.1179/136217199101538012

2. Colegrove, P.A., Shercliff, H.R., Zettler, R. Model For Predicting Heat Generation And Temperature in Friction Stir Welding From The Material Properties Science and Technology of Welding \& Joining 12 (4) 2007: pp. 284-297.

3. Bozkurt, Y., Kentli, A., Uzun, H., Salman, S. Experimental Investigation and Prediction of Mechanical Properties of Friction Stir Welded Aluminium Metal Matrix Composite Plates Materials Science 18 (4) 2012: pp. 336-340.

4. Selvamani, S.T., Umanath, K., Palanikumar, K. Heat Transfer Analysis during Friction Stir Welding of A16061-T6 Alloy International Journal of Engineering Research and Application (IJERA) 1 (4) 2011: pp. 1453-1460.

5. Vilaça, P., Quintino, L., Santos, J.F. iSTIR-Analytical Thermal Model for Friction Stir Welding Journal of Materials Processing Technology 169 (3) 2005: pp. 452-465.

6. Mishra, R.S., Ma, Z.Y. Friction Stir Welding and Processing Materials Science and Engineering R: Reports 50 (1) 2005: pp. $1-78$.

7. Zhang, Z., Qi, W.U., Zhang, H.W. Numerical Studies of Effect of Tool Sizes and Pin Shapes on Friction Stir Welding of AA2024-T3 Alloy Transactions of Nonferrous Metals Society of China 24 (10) 2014: pp. 3293-3301.

http://dx.doi.org/10.1016/S1003-6326(14)63469-5
8. Chen, C.M., Kovacevic, R. Finite Element Modeling of Friction Stir Welding-Thermal and Thermo Mechanical Analysis International Journal of Machine Tools \& Manufacture 43 2003: pp. 1319-1326.

9. Zhang, H.W., Zhang, Z., Chen, J.T. The Finite Element Simulation of the Friction Stir Welding Process Materials Science and Engineering A 403 2005: pp. 340-348.

10. Kıral, B.G., Tabanoğlu, M., Serindağ, H.T. Finite Element Modeling of Friction Stir Welding in Aluminum Alloys Joint Mathematical and Computational Applications 18(2) 2013: pp. $122-131$.

11. Chao, Y.J., Qi, X., Tang, W. Heat Transfer in Friction Stir Welding - Experimental and Numerical Studies Transactions of the ASME 125 2003: pp. 138-145.

12. Schmidt, H.B., Hattel, J.H. Thermal Modelling of Friction Stir Welding Scripta Materialia 58 (5) 2008: pp. 332-337.

13. Donne, C.D., Lima, E., Wegener, J., Pyzalla, A., Buslaps, T. Investigation on Residual Stresses in Friction Stir Welds 3rd International Symposium on Friction Stir Welding 2001: pp. 1-10.

14. Djelosevic, M., Gajic, V., Petrović, D., Bizic, M. Identification of Local Stress Parameters Influencing the Optimum Design of Box Girders Engineering Structures 40 2012: pp. 299-316.

15. Miller, A.K. Unified Constitutive Equations for Creep and Plasticity. Elsevier Applied Science, London, 1987. http://dx.doi.org/10.1007/978-94-009-3439-9

16. Nandan, R., Roy, G.G., Lienert, T.J., DebRoy, T. Numerical Modelling of 3D Plastic Flow and Heat Transfer During Friction Stir Welding of Stainless Science and Technology of Welding \& Joining $11(5)$ 2006: pp. 526-537.

17. Song, M., Kovacevic, R. Thermal Modeling of Friction Stir Welding in a Moving Coordinate System and Its Validation International Journal of Machine Tools and Manufacture 43 (6) 2003: pp. 605-615.

18. Arora, K.S., $\quad$ Pandey, S., $\quad$ Schaper, M., Kumar, R. Microstructure Evolution During Friction Stir Welding of Aluminum Alloy AA2219 Journal of Materials Science \& Technology 26 (8) 2010: pp. 747-753. http://dx.doi.org/10.1016/S1005-0302(10)60118-1

19. Schmidt, H., Hattel, J., Wert, J. An Analytical Model for the Heat Generation in Friction Stir Welding Modeling and Simulation in Materials Science and Engineering 40 2004: pp. $143-157$. http://dx.doi.org/10.1088/0965-0393/12/1/013

20. Hamilton, C., Dymek, S., Sommers, A. A Thermal Model of Friction Stir Welding in Aluminum Alloys International Journal of Machine Tools \& Manufacture 48 2008: pp. 1120-1130.

21. Ulysse, $\mathbf{P}$. Three-Dimensional Modeling of the Friction StirWelding Process International Journal of Machine Tools and Manufacture 42 (14) 2002: pp. 1549-1557. http://dx.doi.org/10.1016/S0890-6955(02)00114-1

22. Soundararajan, V., Zekovic, S., Kovacevic, R. ThermoMechanical Model with Adaptive Boundary Conditions for Friction Stir Welding of Al 6061 International Journal of Machine Tools \& Manufacture 45 2005: pp. 1577-1587. http://dx.doi.org/10.1016/j.ijmachtools.2005.02.008

23. Rajamanickam, N., Balusamy, V., Reddy, G.M., Natarajan, K. Effect of Process Parameters on Thermal History and Mechanical Properties of Friction Stir Welds Materials \& Design 30 2009: pp. 2726-2731.

24. Soundararajan, V., Valant, M., Kovacevic, R. An Overview of R\&D Work in Friction Stir Welding at SMU Journal of Metallurgy 12 (204) 2006: pp. 277-295.

25. Thomas, W.M., Johnson, K.I., Wiesner, C.S. Friction Stir Welding-Recent Developments in Tool and Process Technologies Advanced Engineering Materials 5 (7) 2003: pp. 485-490. 